cal need for social legitimacy. However, a major factor in his success was undoubtedly the rigorous training in gas analysis that he received from Robert Bunsen and his pupil Hermann Kolbe at the University of Marburg, where in 1849 Frankland was the first Englishman to take a PhD. Frankland quickly came to admire German culture and its notion of class based on mind rather than wealth. He was to have it both ways.

Russell provides a fascinating account of chemistry teaching at Owens College, which Frankland ultimately found lacking in challenge, and of his wide-ranging work as a chemical consultant. He had married Sophie Fick, whom he met at Marburg, and his commitments to a growing family drove him into industrial consultancy. Although this gave him financial security, there is evidence that he often compromised himself; he consequently left Manchester with his reputation as an expert witness somewhat clouded. Despite his academic renown, Frankland's permanent connection with 'trade' demeaned him in the eyes of scientific contemporaries, including the other members of the X-club, who denied him the presidency of the Royal Society.

Frankland moved to London in 1857 and, after holding a variety of positions, he finally found scope for his commitment to the communication of science at the Royal College of Chemistry, in succession to A.W. Hofmann. By this time, Frankland had made his name as a great synthetic organic chemist. Russell does not duck some difficult organometallic and synthetic chemistry, but confines it to two technical chapters, and by deft summary in other contexts he provides an overall account that can be understood and enjoyed by scientists from other disciplines, as well as by historians of science.

In 1866, Frankland published Lecture Notes for Chemical Students; like the examinations he set for the Department of Science and Art, this used the concept of valency he had developed in the 1850 s and the graphic use of chemical formulae. Graphic formulae are now such an indispensable part of chemical language for making clear the constitution and structure of compounds that it is difficult to imagine the revolutionary nature and significance of Frankland's innovation.

Frankland became a member of the $\mathrm{X}$-Club in the $1860 \mathrm{~s}$, and came to regard some fellow members, Huxley (and by extension Darwin) and Tyndall, as the modern evangelists who would guide men's thoughts long after the four gospel writers had become obsolete. However, Frankland's religious views - youthful evangelical conversion followed by doubts - were more complicated than simple agnosticism or atheism.

Frankland's family relationships were similarly tortuous. His first wife died in
1873; two years later he married Ellen Grenside, who was not much older than his two daughters. His children were openly hostile to the match. Because all four of Sophie's children kept diaries that have survived, Russell is able to reconstruct this painful episode in detail. And Frankland's relationship with his son Percy (who also became an eminent chemist) deteriorated so far that father and son were not on speaking terms for several years.

Such vivid details of Frankland's private life and fascinating insights into his relationships with other eminent Victorians make this a rich and rewarding read. Frankland was undoubtedly one of Britain's most important and influential nineteenthcentury scientists, and it is good to see him properly honoured at last with a fine biography.

W. H. Brock is in the Department of History, University of Leicester, Leicester LE1 7EH, UK.

\section{Mind of a machine}

\section{William Clocksin}

Impossible Minds: My Neurons, My Consciousness. By Igor Aleksander. Imperial College Press: 1996. Pp. 347. £17.

MANY of the goals of research into machine intelligence have been achieved by biological nervous systems, but using radically different strategies, architectures and hardware. For example, in living neural systems there are no formal or numerical representations; communication media are stochastic; events are asynchronous; components are unreliable and widely distributed; connectivity does not obey precise blueprints; and 'clocking' speeds are millions of times slower than in digital computers. Yet the performance of natural systems in real-time tasks entailing perception, learning and motor control, in unpredictable and perilous environments, remains unrivalled.

How can they be so effective? Can any underlying principles be exposed and incorporated within new artificial systems? Can artificial systems designed on the principles of electronics approach the performance of natural systems?

Igor Aleksander seeks to answer these questions, and his book provides a popular account of the problem of consciousness. It is a personal view, from the perspective of a plain-speaking and clearsighted engineer, articulated with all the optimism and confidence that engineers need to pursue the audacious goal of designing intelligent and conscious robots.

The core of the book is constructed around three interleaved stories. The first is about Magnus, a suite of software being developed by Aleksander and his colleagues to establish whether state machines with a feedback path from output to input can display complex behaviours and 'mental' operations. Magnus also serves as the engineer's ever-present focus on the artefact. The hypothetical Magnus of the future is described and represented with the same conviction as the primitive work-in-progress Magnus that runs on a desktop computer in London. The story culminates with a hypothetical conversation between Magnus and a journalist in the year 2030 .

A parallel science-fiction story is presented with one episode at the end of each chapter. It describes a world in which robotic life-forms debate whether humans are conscious.

But the main story is built around Aleksander's "basic guess", which supposes that consciousness is determined by the firing patterns of neurons. This is followed by thirteen consequences, dealing with topics such as representation, language learning, instinct and emotions. The technical issues unfolded in this story are given in terms of state-machine automata with feedback and a novel iconic representation of percepts and memories. That might sound daunting, but readers do not need to know details of the theory or implementation.

This book is different from many popular books on consciousness in that there is emphasis on the social life of the robot as a useful input for conditioning its experience and learning language. The robot's principal contact with memories and behaviours other than its own comes from what Aleksander calls the "societal repository". Although this attention to culture and society represents an advance on current views in the machine-intelligence community, it is clear to me that a more radical approach is called for, in which the mind and consciousness are a construction of the organism's engagement with its cultural and social matrix. So instead of Kelly's personal construct theory, the main influence from psychology in this book, perhaps designers of the next Magnus should turn for psychological inspiration to the Milan school of systemic practice, itself inspired, ironically enough, by cybernetic principles.

This book touches on philosophy, psychology, cybernetics, artificial intelligence and electrical engineering, but does not engage with any particular issue in much technical depth. Rather, it is more of an 'ideas' book, and was fun to read. It should be an adventure and an inspiration for the human, if not yet the robotic, mind.

William Clocksin is at the Computer Laboratory, University of Cambridge, Cambridge CB2 3QG, UK. 